\section{Estrogen Therapy for Postmenopausal Osteoporosis}

Lorraine A. Fitzpatrick

Osteoporosis is a worldwide problem that results in fractures that lead to disability and high costs to society. Estrogen therapy is frequently utilized for postmenopausal symptoms, but also has proven protective effects on the skeleton. The main action of estrogen at the cellular level is to inhibit the osteoclast by increasing levels of osteoprotegerin (OPG). OPG binds to the receptor activator of NFkB and prevents osteoclast differentiation, activity and survival. Numerous trials have demonstrated the positive effect estrogen has on the improvement of bone mineral density, and lower doses have also proven efficacious with fewer side effects. Both observational and randomized clinical trials have demonstrated the ability of estrogen treatment to prevent fractures. Topics that remain controversial include the appropriate length of estrogen treatment for postmenopausal women and the appropriate follow-up after treatment discontinuation. (Arq Bras Endocrinol Metab 2006;50/4:705-719)

Keywords: Estrogen; Osteoporosis; Bone mineral density; Fractures; Estradiol

\title{
RESUMO
}

Terapia Estrogênica Para Osteoporose na Pós-Menopausa.

Osteoporose é um problema universal que resulta em fraturas e leva a incapacidade e alto custo para a sociedade. A terapia estrogênica é freqüentemente utilizada nos sintomas da pós-menopausa, mas também tem comprovado efeito protetor no esqueleto. A principal ação a nível celular é inibir os osteoclastos por causa do aumento dos níveis de osteoprotegerina (OPG). A OPG liga-se ao receptor ativador do NFkB e impede a diferenciação, atividade e sobrevida dos osteoclastos. Numerosos estudos demonstraram o efeito positivo do estrogênio na melhora da densidade mineral óssea e doses mais baixas apresentam comprovada eficácia com menos efeitos colaterais. Tanto os estudos observacionais como os clínicos demonstraram a capacidade da terapia estrogênica na prevenção de fraturas. Alguns tópicos permanecem em controvérsia, como a terapia prolongada e um seguimento adequado após a descontinuação do tratamento. (Arq Bras Endocrinol Metab 2006;50/4:705-719)

Descritores: Estrógeno; Osteoporose; Densidade mineral óssea; Fraturas; Estradiol

$\mathbf{O}$ TEOPOROSIS IS A MAJOR PUBLIC health problem affecting an estimated 75 million women in Europe, Japan, Australia and North America (1). In 1990, the global burden of hip fractures was assessed and it was estimated that there were 1.31 million new hip fractures and the prevalence of hip fractures with disability was 4.48 million. Hip fractures represented $0.1 \%$ of the overall global burden of disease (2). In an attempt to assess the cost of fracture, a retrospective cohort study was conducted in 2000 in the United 
States. Mean total costs per patient per year were highest for fractures of the hip (US\$ 26,856), femur (US\$ 14,805 ) and tibia (US\$ 10,224). Approximately 13\% of the fractures required long-term care and $84 \%$ required an inpatient setting (3).

The relationship of estrogen depletion and bone loss has been well established and it is estimated that estrogen deficiency is responsible for $75 \%$ of bone loss that occurs in postmenopausal women. Immediately after the menopause, bone mass decreases by 3 to $5 \%$ per year and increased bone turnover is associated with increased bone loss and the risk of fractures. It is estimated that 1.5 million people suffer from a bonedisease related fracture annually (4). A white woman over the age of 50 has a better than $40 \%$ chance of having a fracture during her life-time (5). Epidemiologic studies support an estimate of a 50 to $60 \%$ reduction in wrist and hip fractures with estrogen replacement therapy.

Estrogen has proven to be efficacious in increasing bone mineral density and preventing fractures. However, recent research on the side effects after long-term use of estrogen therapy has reduced the use of this pharmaceutical agent for the treatment of osteoporosis. The side effects and potential risks have frightened both health care providers and patients from prescribing or taking this medication. Overall, absolute risks are low for healthy women, although each patient should have an individual risk assessment prior to taking estrogen.

There are many reasons why women will discontinue medications in general, but estrogen compliance is particularly fraught with hazard. Fifty percent of women discontinue therapy within months and 10\% use the medication sporadically. Even prior to the results of the Women's Health Initiative, $23 \%$ of women never fill their prescription and at the end of 3 years only $20 \%$ continue to take HRT (6). It is well documented that hormone replacement therapy initiated soon after the menopause will reduce or reverse the bone loss that normally occurs at that time.

\section{CELLULAR IN VIVO EFFECTS OF ESTROGEN ON BONE}

Osteoporosis is a complex, polygeneic disorder and is likely to be caused by multifaceted interactions among systemic and local cytokines and growth factors that regulate bone cell function. The effects of estrogen on bone are mediated through the estrogen receptor alpha $(\mathrm{ER} \alpha)$, which is found on osteoprogenitors and in normal human bone (7). Evidence suggests that ER $\alpha$ and an orphan receptor designated ERR $\alpha$ may be involved in bone formation, maintenance and turnover through a number of complex pathways (8).

The major action of estrogen is to inhibit bone resorption by the action of estrogen on the osteoclast. Osteoclasts are derived from the macrophage/monocyte lineage of hematopoietic stem cells. Evidence in multiple species suggests that the direct action of estrogen on the osteoclast is mediated by regulation of specific genes. Estrogen also induces apoptosis of osteoclasts, resulting in a reduced lifespan of this bone-resorbing cell.

Three members of the TNF and TNF receptor superfamily are responsible for the regulation of bone resorption (9). Osteoblasts produce receptor activator of NFkB ligand (RANKL), the ligand for RANK, a receptor found on hematopoietic cells. The binding of RANKL to RANK promotes the differentiation of hematopoietic precursor cells into osteoclasts. The RANK/RANKL signaling pathway is an essential regulator of osteoclast development and activity. Osteoblasts also produce and secrete a protein called osteoprotegerin (OPG). OPG serves as a decoy receptor and binds to RANK, preventing the binding of RANKL to RANK. Studies in transgenic mice that overproduce OPG, which blocks RANKL/RANK interactions, resulted in a skeletal phenotype consistent with osteopetrosis (10), while OPG knockout mice had a phenotype consistent with severe osteoporosis and a high incidence of fracture (11). Estrogen down regulates a number of cytokines and growth factors such as interleukin-1, interleukin-6, and tumor necrosis factor that exert their efforts through the RANK/RANKL pathway. The inhibition of these cytokines by estrogen inhibits RANK/RANKL binding and results in decreased in osteoclast activity, and survival function. In addition, estrogen stimulates the production of OPG by osteoblasts, which prevents RANK ligand from binding to RANK. Thus, the presence of estrogen prevents the binding of RANKL to RANK which results in the inhibition of the formation, differentiation and survival of osteoclasts.

To test the hypothesis that increases in RANKL occur during estrogen deficiency, Eghbali-Fatourechi and colleagues evaluated RANKL on human bone marrow mononuclear cells in premenopausal and postmenopausal women by cytometry. Bone marrow mononuclear cells from 12 premenopausal women, 12 untreated postmenopausal women and 12 postmenopausal women receiving estrogen therapy were characterized as marrow stromal cells (MSCs), T cells, 
or B cells. Approximately 1\% of MSCs expressed RANKL and were able to form mineralized nodules in culture, a marker for the osteoblast phenotype. There was a 2 - to 3 -fold increase in the relative fluorescence intensity of OPG in the estrogen-deficient postmenopausal women. OPG fluorescence correlated directly with bone resorption markers in all RANKLexpressing cell types and was negatively correlated with serum $17 \beta$-estradiol levels. The authors suggest a physiologic causal relationship, with the caveat that the data do not support a direct effect of estrogen on RANKL activity. Estrogen could act indirectly by increasing the levels of cytokines known to stimulate RANKL such as IL- $1 \alpha$, PGE- 2 and TNF- $\alpha$. Evaluation of bone marrow cells provided additional insights into the mechanism of action of the RANKL/RANK/ OPG pathway since circulating levels of RANKL and OPG were not different among the three groups of women. Overall this study indicates that RANKL, a final effector of osteoclast formation and function is increased by estrogen deficiency and decreased by estrogen sufficiency in bone marrow cells, implicating the critical role of estrogen in the pathogenesis of postmenopausal osteoporosis (12).

\section{GENETIC MUTATIONS THAT ADVANCE THE UNDERSTANDING OF THE ROLE OF ESTROGEN IN THE DEVELOPING SKELETON}

The role of estrogen in human skeletal maturation and the importance of small amounts of circulating estrogen became apparent with the discovery of two genetic disorders. One patient had a point mutation in the estrogen receptor gene providing a clinical picture consistent with estrogen resistance. This 27-year-old man presented with tall stature and continued linear growth. Skeletal maturation was estimated at 15 years and osteoporosis confirmed by dual energy $\mathrm{x}$-ray absorptiometry (13). A second set of patients (one male, one female) with aromatase deficiency was described and these patients were unable to convert androgens to estrogens $(14,15)$. The male patient had estrogen insensitivity with tall stature, delayed skeletal maturation and osteopenia. Plasma levels of testosterone, $5 \alpha$-dyhydrotestosterone, and androstenedione were markedly elevated. Administration of exogenous estrogen resulted in rapid accredation of bone mineral density and cessation of linear growth. These two genetic disorders have demonstrated the importance of estrogen in the development of peak bone mass, skeletal maturation and mineralization.
Studies evaluating single nucleotide polymorphisms (SNPs) of ER $\alpha$ may be associated with bone fragility (16). In a large multicenter study, 1 of the SNPs for ER $\alpha$ was associated with a significant reduction in fracture risk. Conversely, there was no association with bone mineral density with this polymorphism. The odds of fracture were reduced $20 \%$ in subjects with xbaI polymorphism in the ER $\alpha$ gene. Other studies have suggested that specific SNPs in the ER $\alpha$ gene regulate both bone mineral density and fracture rates.

Clinical studies have revealed the importance of small doses of estrogen in men. In an elegant clinical study, endogenous testosterone and estrogen production were blocked in 59 elderly men and then physiologic testosterone and estrogen were replaced. After withdrawal of both testosterone and estrogen and then withdrawing only one hormone or the other the impact on bone turnover was assessed. Bone resorption markers increased significantly in the absence of both hormones and were unchanged in men in which both hormones were replaced. In this study, estrogen played the major role in preventing the increase in bone resorption markers. In contrast, testosterone had no significant effect. The study concluded that estrogen is the dominant sex steroid regulating bone resorption and both testosterone and estrogen are important in maintaining bone formation, as assessed by osteocalcin measurements (17).

\section{CLINICAL STUDIES: THE EFFECT OF ESTROGEN ON BONE MINERAL DENSITY}

Early cross-sectional studies recognized that estrogen deficiency at the time of the menopause was associated with bone loss. Women who experienced premature menopause had lower bone mineral density measurements at the hip and spine in comparison to premenopausal age-matched controls (18). At the time of either natural or surgical menopause, there is a rapid phase of bone loss with a rate of loss as high as 3\% per year for about 5 years (19). Bone loss decelerates at this time to a rate of $0.5-1.0 \%$ per year.

Studies have also demonstrated that estradiol levels, even at low postmenopausal levels, are associated with bone loss. In women, estradiol levels vary greatly in the postmenopausal range, from undetectable up to $25 \mathrm{pg} / \mathrm{ml}$. If women are divided into tertiles of serum estradiol levels, bone mineral density varies greatly and is highest among those with the higher detectable levels of estradiol (20). The skeletal effects of endogenous serum estradiol were assessed in 
274 women 65 years or older who participated in the study of osteoporotic fractures. Vertebral deformities were less prevalent among women whose estradiol level exceeded $5 \mathrm{pg} / \mathrm{ml}$ (multiple adjusted odds ratio $0.4 ; 95 \%$ confidence interval, 0.2-0.8). Looking at various tertiles, women who had estradiol levels from 10 to $25 \mathrm{pg} / \mathrm{ml}$ had $4.9 \%, 9.6 \%, 7.3 \%$, and $6.8 \%$ greater $\mathrm{BMD}$ at the total hip, calcaneous, proximal radius and spine compared to women whose estradiol levels were $<5 \mathrm{pg} / \mathrm{ml}(20)$.

Even after treatment, absolute estradiol levels can impact the skeleton. In a longitudinal study, the rate of bone loss was significantly greater in women in the lowest tertile of estradiol levels at the lumbar spine and total body (both $\mathrm{p}<0.05$ ) as compared to women with estradiol levels in the highest tertile (21). These levels of bioavailable estrogen after treatment with conjugated equine estrogen (CEE) also affected the response to hormone therapy (HT) with a greater increase in BMD at femoral sites and total body in the women initially in the lowest tertile of estradiol levels.

Several observational studies have indicated that estrogen can attenuate the fracture risk. For example, the risk of any nonvertebral fracture in a population that continuously used estrogen was $19.6 \%$ compared with a $30.9 \%$ incidence in never users (22). Many of these observational studies are excellent, but there may be inherent bias that occurs with these study designs. For example, there may be bias in the women who enter the study in that they may be healthier, have a higher socio-economic status, and be more compliant all of which can decrease the fracture risk. On the other hand, an increase in fracture risk could occur if the bias was to include more women with premature menopause, or have a history of osteoporosis or fracture, or have a lower BMI to be in the study. Fortunately, there are several prospective, randomized, double-blind placebo-controlled studies that evaluate the effect of estrogen on BMD and fracture.

One of the early randomized, double-blind, placebo-controlled studies that focused osteoporosisrelated outcomes was the Postmenopausal Progestin Intervention (PEPI) Trial (23). This 3-year, multicenter trial evaluated a total of 875 women aged 45-64 years. Subjects were treated with placebo, conjugated equine estrogen (CEE) $0.625 \mathrm{mg} / \mathrm{d}$, CEE 0.625 $\mathrm{mg} / \mathrm{d}$ plus medroxyprogesterone acetate (MPA) 10 $\mathrm{mg} / \mathrm{d}$ for $12 \mathrm{~d} /$ month, CEE $0.625 \mathrm{mg} / \mathrm{d}$ plus MPA $2.5 \mathrm{mg} / \mathrm{d}$ or CEE $0.625 \mathrm{mg} / \mathrm{d}$ plus micronized progesterone (MP) $200 \mathrm{mg}$ for $12 \mathrm{~d} /$ month. Bone mineral density was measured at baseline, 12 and 36 months. The placebo group lost BMD at the lumbar spine $(-1.8 \%)$ and hip $(-1.7 \%)$ while those on active treatment gained BMD at both sites. BMD increased at the lumbar spine from 3.5 to $5.0 \%$ with a mean total increase of $1.7 \%$ of BMD at the hip among the active treatment groups. Among adherent participants, the change in BMD did not vary by treatment at these two sites. Older women, women with baseline low BMD and those without a history of previous hormone therapy had significantly greater increases in BMD compared to younger women, women with higher initial BMD and those who had used hormones previously.

\section{RESULTS FROM THE WOMEN'S HEALTH INITIATIVE (WHI)}

The WHI demonstrated unequivocally that estrogen, with or without progestin, reduced fracture risk. The WHI was a randomized, double blind placebo-controlled multicenter study. There were two studies, the first of which consisted of women who had an intact uterus and were randomized to placebo or 0.625 $\mathrm{mg} / \mathrm{d}$ CEE plus MPA $2.5 \mathrm{mg} / \mathrm{d}$. A total of 16,608 women aged 50-79 years were included in this group. The primary outcome measure was coronary heart disease with invasive breast cancer as the primary adverse outcome. After a mean of 5.2 years of follow-up, the data and safety monitoring board recommended stopping the trial because the test statistic for invasive breast cancer exceeded the conservative, preset stopping boundary. In addition, a global index, to assess risks vs. benefits also supported this decision (24). All confirmed osteoporotic fracture events that occurred from the time of enrollment until discontinuation of the trial were assessed and BMD was measured in a subset of subjects $(n=1024)$ at baseline, 12 and 36 months.

Fractures were found in $8.6 \%$ of women in the HT-treated group and $11.1 \%$ of placebo-treated patients experienced a fracture with a hazard ratio of 0.76 (95\% confidence interval [CI], 0.69-0.83). Hip and clinical vertebral fractures were significantly reduced by $34 \%$ and total osteoporotic fractures by $24 \%$ in the active treatment group compared to placebo (figure 1). There was no evidence that the efficacy of HT differed according to any risk factors for fractures such as BMI, age, smoking, history of falls, calcium intake, past use of hormones, or personal and family history of fractures. HT was efficacious in women regardless if they were at low, medium, or high risk of fracture (25).

Another group of women who were evaluated had undergone a hysterectomy and did not need MPA 
for uterine protection. The 10,739 subjects in this group received $0.625 \mathrm{mg} / \mathrm{d}$ of conjugated equine estrogen alone or placebo and were from 50-79 years of age. The intervention phase of this trial was ended early with an average follow-up of 6.8 years. Hip fracture rates were 11 vs. 17 per 10,000 person-years $(\mathrm{p}=$ 0.01 ), clinical vertebral fractures, 11 vs. 17 per 10,000 person-years $(p=0.02)$ and total osteoporotic fractures, 139 vs. 195 per 10,000 person-years $(\mathrm{p}<0.001)$ in the CEE vs. placebo-treated subjects. The hazard ratio of hip fracture on estrogen therapy was 0.61 (nominal 95\% CI, 0.41-0.91), for vertebral fractures was 0.65 (nominal 95\% CI, 0.42-0.93) and for total fractures was 0.70 (nominal 95\% CI, 0.63-0.79). Exploratory analyses indicated that there were no major interactions on subject characteristics and major clinical outcome event rates. Specifically, there were no interactions with hip fracture and ethnicity or BMI. An analysis for "compliers" estimated lower risks of hip fracture (HR, 0.048 ) compared to the intention-to-treat analysis. At the time of study termination, $53.8 \%$ of women had already stopped study medication and dropout rates exceeded design projections (26).

One of the unusual findings in the WHI is the fact that the subjects were not selected for bone loss, yet they attained fracture prevention benefit from treatment with HT. A small subset of women $(\mathrm{n}=$ $1,024)$ had BMD measured who were thought to represent the entire cohort. The number of women who

\section{WHI Results: Effect of Hormone Therapy in Preventing Fractures}
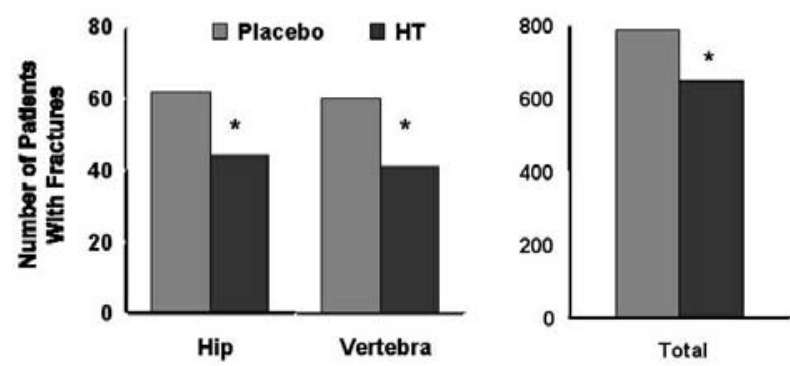

Figure 1. Results from the Women's Health Initiative. A total of 16,608 women aged 50-79 years were randomized to combination of conjugated equine and progestin or placebo. Mean follow-up was 5.2 years. Vertebral, non-vertebral, lower arm and wrist, and all fractures combined were significantly reduced in patients treated with hormone therapy compared to placebo. (Adapted from Writing Group for the Women's Health Initiative Investigators. JAMA 2002;288:321-33) were osteoporotic at the hip was small: $4 \%$ were osteoporotic at the total hip in the HT group compared to $6 \%$ in the placebo group. Even with the small number of subjects with osteoporosis, hip fracture was reduced by $33 \%$ by treatment. In a subgroup analysis, hormone therapy decreased the risk of hip fracture by $60 \%$ among women with an adequate baseline calcium intake defined as $1,200 \mathrm{mg} / \mathrm{d}$. To compare the fracture benefit with the amount of change in BMD, there was an increase in total hip BMD of $3.7 \%$ by the end of year 3. Thus, the WHI was the first randomized clinical trial to demonstrate that combination hormone therapy reduced fracture risk at the hip, spine and wrist, even in women who did not meet the WHO diagnostic criteria for osteoporosis. These findings of reduced risk for fracture are consistent with observational studies and several meta-analyses of the efficacy of HT. These findings are different from the bisphosphonate trials in which risk reduction of hip and nonspine fractures were only seen in women with osteoporosis, but not in women without osteoporosis (27$30)$. The reasons for these differences have been speculated to relate to muscle strength, although there is very little, if any, evidence to support this hypothesis.

Several issues regarding the WHI have limited the applicability of the conclusions. A high proportion of women did not receive the treatment to which they were randomized. The number of women who discontinued their medication was disproportionately high in the HT group. Presumably, dropout rates were higher due to a higher incidence of adverse events such as vaginal bleeding. The authors note that if discontinuation of treatment and initiation of non-study treatment occurred independently of risk factors for clinical outcomes, their intention to treat analysis underestimates both the harms and benefits of HT among women who adhere to therapy (24). There were also a disproportionate number of women who were unblinded in the HT group compared to the placebo group ( $40 \%$ vs. $6 \%$ ) mainly due to persistent vaginal bleeding, and this differential unblinding may have resulted in higher detection rates of otherwise undetectable myocardial infarction in the HT group (31). A detection bias would most likely not be of the magnitude, however, to explain the differences among the groups.

Women with intolerable menopausal symptoms and that are at low risk for cardiovascular disease are excellent candidates for HT. Usually the benefits of symptom relief outweigh the small absolute risks of harm that might arise from short-term use. In the younger immediate postmenopausal group, a subanalysis of women aged 50-59 years indicated that the 
absolute risk of venous thromboembolism was at an overall rate of $0.5 \%$ for women taking HT for 5 years. The risk for thromboembolism in the HT increased to $1.4 \%$ for obese women. The risk of breast cancer associated with estrogen with or without progestin was evaluated in the WHI. The risk of breast cancer is slightly increased with combined estrogen and progestin after 3 years of use. In the CEE-only treated subjects, treatment for a mean of 7.1 years did not increase breast cancer incidence and in an exploratory analyses, ductal carcinomas were reduced. Other issues regarding negative effects on cognition must also be considered in the evaluation of the patient prior to initiation of estrogen, with or without progestogen.

In summary, the WHI provided compelling evidence that estrogen alone or in combination with progestin reduced the risk of hip, clinical vertebral and other fractures. The reduction in fracture risk was similar to that seen in observational studies and metaanalyses. Problems with the trial include that fact that only one type and dose of estrogen was tested, and analyses of differences between the HT trial and the trial that used estrogen alone, for which data are forthcoming. Hormone therapy was initiated in an older group of women than might be seen in usual clinical care, and thus the applicability of some of the endpoints have been questioned. High rates of study medication discontinuation and increased rates of crossover between groups are further limitations to the interpretation of the study results. Sensitivity analyses suggested that the lack of adherence to assigned study medication might have underestimated the effects for both the benefits and the risks assessed in these trials.

As a result of the publicity surrounding the results of the $\mathrm{WHI}$, including the risks, many women discontinued their HT. In a telephone survey of 670 women who participated in a large HMO organization, the investigators assessed the level of knowledge of the results and whether the results influenced the decision to remain on HT or discontinue therapy (32). The average age range was from 50-69 years and women had been on estrogen for at least 1 year. Ninety-three percent of women had heard of the results of the WHI in some format (21\% mass media, 32\% health care plan, and 34\% health care providers). Regardless of the source of the data, only $59 \%$ felt that the quality of the information was good. Overall, the subjects' knowledge base was poor as $64 \%$ did not know what the findings were and only $23 \%$ had correct knowledge regarding the results of the trial. In spite of this, $56 \%$ tried to discontinue therapy within the 6-8 months of the date the results were publicly released.

\section{THE MILLION WOMEN STUDY}

A population based, prospective study was designed to assess the health effects of hormone therapy. More than 1 million women were recruited from 1996 to 2001 and follow-up questionnaires were collected 2 to 3 years after initial recruitment on the use of hormone therapy. This study allowed the collection of fracture data in a very large group of women. Average follow-up was 2.8 years with a range of 1.9-3.9 years. A total of 3.7\% $(5,197$ out of 138,737$)$ postmenopausal women reported 1 or more fractures, with $70 \%$ resulting from falls. The incidence of fracture was significantly reduced in current users of hormone therapy with a relative risk of 0.62 (95\% CI, 0.58-0.66; $\mathrm{p}<0.001$ ). The effect of estrogen was protective soon after initiation of hormone therapy and the relative risk decreased with increasing duration of use. The relative risk did not vary according to the type or dose of estrogen, nor if progestogens were included. Past users of hormone therapy use had no significant protection against fractures and incidence rates returned to those of never-users within about a year of ceasing use. The authors concluded that all types of hormone therapy offered substantial protection against fracture during active use. The older the woman was, the greater the absolute reduction in fracture incidence while on hormone therapy (33).

\section{META-ANALYSIS OF ESTROGEN THERAPY}

A Cochrane systematic review of randomized controlled trials has been published (34) and updated to include the WHI results at the NIH Consensus Development Conference on Osteoporosis (35). Studies included randomized controlled clinical trials of at least 1 year in duration and were identified from MEDLINE (1966 to 1998) and the Cochrane Library Controlled Clinical Trials Register. Results in measurement of BMD were similar in comparing prevention to treatment trials, opposed vs. unopposed HT, transdermal vs. oral estrogen and types of progestogen. Duration and dose affected BMD results. HT showed a trend toward reduced risk of vertebral fractures Relative Risk (RR) 0.66, 95\% CI, 0.41-1.07) and nonvertebral fractures (RR 0.87, 95\% CI, 0.71-1.08) (figure 2).

\section{THE EFFECT OF ESTROGEN ON BONE GEOMETRY}

The importance of bone geometry cannot be underestimated, in spite of little correlation with fracture risk 


\section{Meta-Analysis of Osteoporosis Therapies: Nonvertebral Fractures}

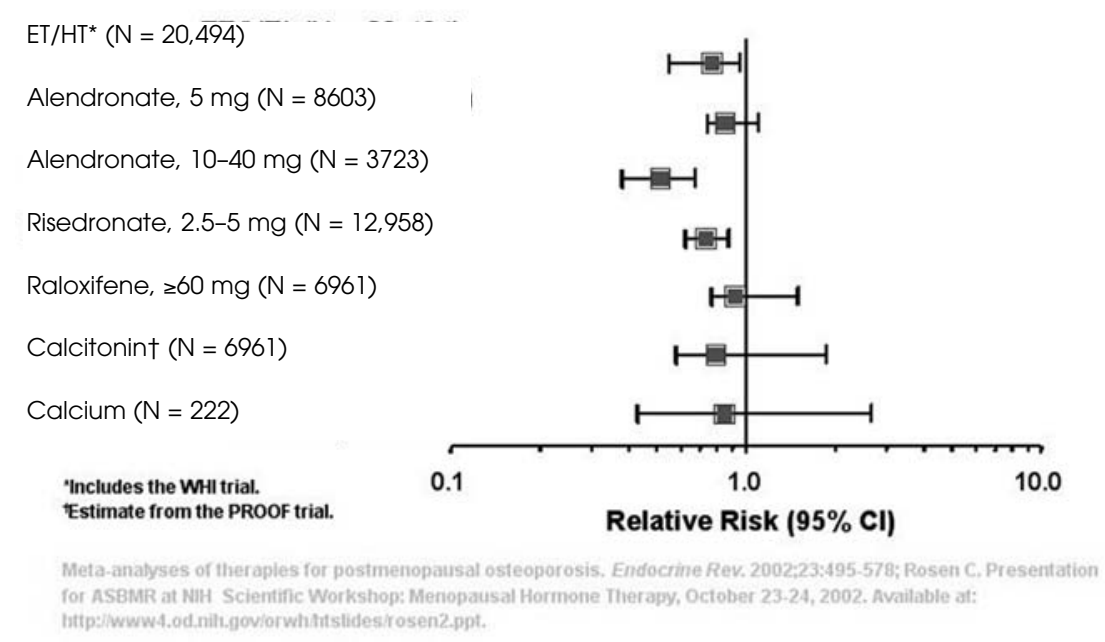

Figure 2. Meta-analysis of osteoporotic therapies: Relative risk of non-vertebral fractures. Randomized controlled trials of at least one-year duration were compared.

in clinical studies. This relatively nascent field has provided insights into the changes in bone architecture and strength with therapy. Initial recognition of the possible effects of estrogen on bone geometry was noted in a study of postmenopausal women who had radial BMD measured sequentially by single-photon absorptiometry annually for 15 years. The annual decrease in bone mineral density was $1.9 \%$ in these 108 postmenopausal women. Medullary bone diameter increased annually by $1.1 \%$ and the periosteal diameter by $0.7 \%$. Overall, the strength index decreased by $0.7 \%$. Estradiol levels correlated with changes in the periosteal diameter and with changes in bone mineral density. For each standard deviation decrease in the strength index at baseline, there was an associated risk ratio for fracture at the distal radius of 3.8 (95\% CI, 1.8 to 8.0$)(36)$.

Several reports have utilized Hip Structural Analysis (HSA) to determine femoral geometry with varying pharmacologic treatments. In a double-blind, placebo-controlled, randomized clinical trial of postmenopausal women, Greenspan et al. evaluated changes in femoral bone geometry in patients who were administered CEE $(0.625 \mathrm{mg} / \mathrm{d})$, alendronate $(10 \mathrm{mg} / \mathrm{d})$ or both. There was a significant increase in the femoral neck diameter and section modulus $(+1.4 \%$ and $+3.5 \%$, respectively) in the placebo group, but no changes in Cross Sectional Area (CSA) or cortical thickness. In all treatment groups, there were significant increases in bone CSA, cortical thickness and section modulus compared to baseline and to placebo. In the estrogen treated subjects, there was an increase of $5.8 \%$ and $6.9 \%$ in the section modulus at the intertrochanter and narrow neck. The authors suggest that these types of measurements may contribute to the fracture risk reduction with treatment (37).

\section{CLINICAL STUDIES OF LOW-DOSE ESTROGEN}

Previously, there existed the dogma that the lowest dose of estrogen replacement therapy for bone loss has been $0.625 \mathrm{mg} / \mathrm{d}$ of conjugated estrogen or its equivalent of $1 \mathrm{mg} / \mathrm{d}$ of estradiol. This premise has been tested in randomized, controlled clinical trials. Early studies with low doses of estrogen may not have demonstrated efficacy and were often problematic possibly because vitamin $\mathrm{D}$ and calcium intake may not have been adequate and may have masked the efficacy of estrogen. In addition, the level of estrogen required to maintain relatively normal bone remodeling in older postmenopausal women is lower than that required to stimulate classic target tissues such as the uterus and breast (38).

As early as 1987, Ettinger et al. (39) indicated that doses of $0.3 \mathrm{mg}$ of $\mathrm{CEE}$, when combined with calcium administration, prevented bone loss as compared to placebo. Subjects were within 3 to 36 months 
of the menopause and those with low spinal bone mineral content were excluded. One of the potential problems with the interpretation of this study is that patients were allowed to select their treatment. This, of course, would enhance compliance rates, but also allow for bias to occur. Treatment choices included no treatment, $1500 \mathrm{mg} / \mathrm{d}$ of calcium with calcium carbonate, or CEE and $1500 \mathrm{mg} / \mathrm{d}$ of calcium. The HT regimen was CEE $0.3 \mathrm{mg}$ on days $\mathrm{l}$ to 25 , with MPA $10 \mathrm{mg}$ or norathindrone $5 \mathrm{mg}$ per day on days 16-25. BMD was assessed by Quantiated Computer Tomography (QCT) of the spine and hand radiographs. The annual rate of loss in the study was $5 \%$ compared with $9 \%$ in oophorectomized women. The mean 2 -year values showed a significant reduction of $9 \%$ in spinal trabecular mineral content and $1.1 \%$ in combined cortical thickness in women receiving no treatment and a decrease of $10.5 \%$ in spinal trabecular mineral content and $0.8 \%$ cortical thickness in women taking calcium supplements. Women taking both estrogen and calcium showed no significant changes in spinal trabecular mineral content $(+2.3 \%)$ and in metacarpal combined cortical thickness $(-0.2 \%)(39)$.

The Women's Health, Osteoporosis, Progestin, Estrogen (HOPE) study evaluated the efficacy of low doses of conjugated estrogen plus medroxyproges- terone for relief of vasomotor symptoms and vaginal atrophy (40). In this study, subjects were randomized to receive daily $0.625 \mathrm{mg}$ CEE, $0.625 \mathrm{mg}$ CEE plus $2.5 \mathrm{mg}$ MPA, $0.45 \mathrm{mg}$ CEE, $0.45 \mathrm{mg}$ CEE plus MPA $2.5 \mathrm{mg}, 0.45 \mathrm{mg}$ CEE plus MPA $1.5 \mathrm{mg}, 0.3 \mathrm{mg}$ CEE, or $0.3 \mathrm{mg}$ CEE plus MPA $1.5 \mathrm{mg}$. This twoyear, double-blind, placebo-controlled trial had a substudy that measured the changes from baseline in lumbar spine and total hip, total body, bone mineral content, serum osteocalcin and urinary $\mathrm{N}$-telopeptide of type I collagen. At 24 months, all active treatment groups had significant gains from baseline in lumbar spine and hip BMD $(\mathrm{p}<0.001)$ (figure 3$)$. The placebo group had significant loss of BMD at these two sites over the same time period $(\mathrm{p}<0.001)$. Osteocalcin and $\mathrm{N}$-telopeptides of type I collagen were significantly reduced from baseline for all active treatment groups at all time points $(\mathrm{p}<0.001)$ and there were no changes in the placebo group for these parameters. There was a significant increase in BMD in the groups taking $0.625 \mathrm{mg} / \mathrm{d}$ CEE alone compared to those taking $0.3 \mathrm{mg} / \mathrm{d}$ CEE. This prospective study demonstrated the effectiveness of lower doses of CEE. Two 3 -year, placebo-controlled studies of healthy postmenopausal women older than 65 years also found that low-dose estrogen $(0.25$ to $0.3 \mathrm{mg} / \mathrm{d})$ used alone

\section{Effect of Varying Doses of Estrogen Therapy, with or without Progestin on Lumbar Spine BMD}
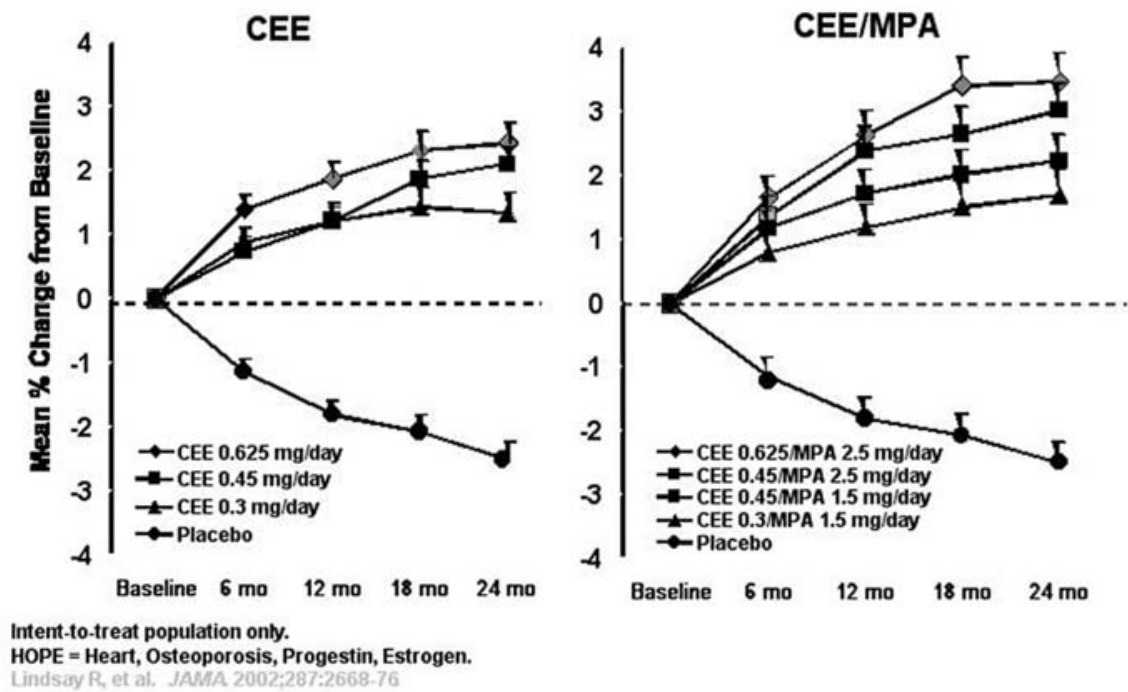

Figure 3. Changes in lumbar spine bone mineral density with varying doses of conjugated equine estrogen with or without progestin.

In the HOPE study, the effect on lower doses of CEE, with or without varying doses of MPA was tested. Smaller doses of CEE $(0.45 \mathrm{mg} / \mathrm{d})$ were equally effective as the higher $(0.625 \mathrm{mg})$ daily dose. The addition of lower doses of MPA made little difference in BMD measurements. (Adapted from Lindsay R, et al. JAMA 2002;287:2668-76) 
or in combination with progesterone significantly increased bone mass and was generally well tolerated $(38,41)$.

Studies with low doses of transdermal estrogen have also demonstrated that lower doses of estrogen can attenuate postmenopausal bone loss. A recently published study evaluated 212 osteopenic women 45-65 years of age in a 2 -year prospective trial. The subjects were treated with $45 \mathrm{ug}$ of $17 \beta$-estradiol combined with 30 or $40 \mathrm{ug}$ levonorgestrel daily or placebo, provided as a 7-day patch. BMD at the lumbar spine, hip and total body increased by 8,6 , and $3 \%$ (all $\mathrm{p}<0.001$ ), respectively. Osteocalcin, bone-specific alkaline phosphatase and urinary C-telopeptides of type I collagen decreased, without any change in urinary calcium excretion. This transdermal combination may offer another alternative to the currently available therapies (42).

Other multicenter double-blinded placebocontrolled studies include a study that randomized women with postmenopausal osteoporosis to transdermal estrogen doses of $0.0235,0.05,0.06$ and 0.1 $\mathrm{mg} / \mathrm{d}$. after 2 years of treatment, all doses resulted in mean increases in BMD of the lumbar spine of 2.37, $4.09,3.28$, and $4.70 \%$, respectively. All increases in BMD were statistically significantly greater than placebo, which decreased at all sites (43).

In a study evaluating the effect of esterified estrogen therapy on bone mineral density (BMD), 406 women were randomized to receive continuous esterified estrogen at doses of $0.3,0.625$, or 1.25 $\mathrm{mg} / \mathrm{d}$, or placebo, for 24 months. All doses of estrogen produced statistically significant increases in BMD compared with placebo. The $0.3-\mathrm{mg} / \mathrm{d}$ dose of estensified estrogen was beneficial to bone health without producing endometrial hyperplasia (44).

One of the interesting questions surrounding HT is the dose and duration of progestogen to use when combination therapy is necessary. Ettinger et al. evaluated a regimen of low-dose estrogen with long-cycle use of progestogen (45). Doses as low as $1.5 \mathrm{mg} / \mathrm{d}$ of MPA may be adequate to protect the endometrium from hyperplasia. Low-dose continuous combined HT resulted in a lower incidence of breakthrough bleeding. Sixmonthly cycles of MPA with low-dose estrogen appeared safe and tolerable, and may increase patient acceptance.

\section{ESTROGEN IN COMBINATION WITH OTHER THER- APIES FOR OSTEOPOROSIS}

The use of combination therapies for osteoporosis has been evaluated in several prospective randomized con- trolled clinical trials. Estrogens have been combined with bisphosphonates, SERMs and teriparatide.

One head-to-head trial compared the effects of alendronate $(10 \mathrm{mg} / \mathrm{d})$ alone, $\operatorname{CEE}(0.625 \mathrm{mg} / \mathrm{d})$ alone, and combination alendronate and CEE to placebo (figure 4). All of the postmenopausal women had undergone a hysterectomy in this study to avoid the confounding variable of progestogen. At the end of 2 years, both CEE alone and alendronate alone significantly increased lumbar spine BMD from baseline ( $6.0 \%$ for both $\mathrm{p}<0.001$ compared to placebo). The group on the combination therapy had significantly better lumbar spine BMD $(8.3 \%, \mathrm{p}<0.001$ vs. placebo and CEE; $\mathrm{p}=0.022$ vs. alendronate) compared to alendronate alone or CEE alone (46).

Changes at the total proximal femur were $+4.0 \%$. $+3.4 \%, 4.7 \%$ and $+0.3 \%$ for alendronate, CEE, alendronate plus CEE and placebo groups, respectively.

A similar study evaluated combination therapy in community-dwelling elderly women. This randomized, double-blind, placebo-controlled trial enrolled subjects who were older than 65 years. After a 3month run-in phase with HT and alendronate placebo, subjects were randomized to CEE $0.625 \mathrm{mg} / \mathrm{d}$ with or without MPA $2.5 \mathrm{mg} / \mathrm{d}$ and alendronate 10 $\mathrm{mg} / \mathrm{d}$, both agents or neither. After 3 years of treatment, BMD was significantly greater at all femoral and

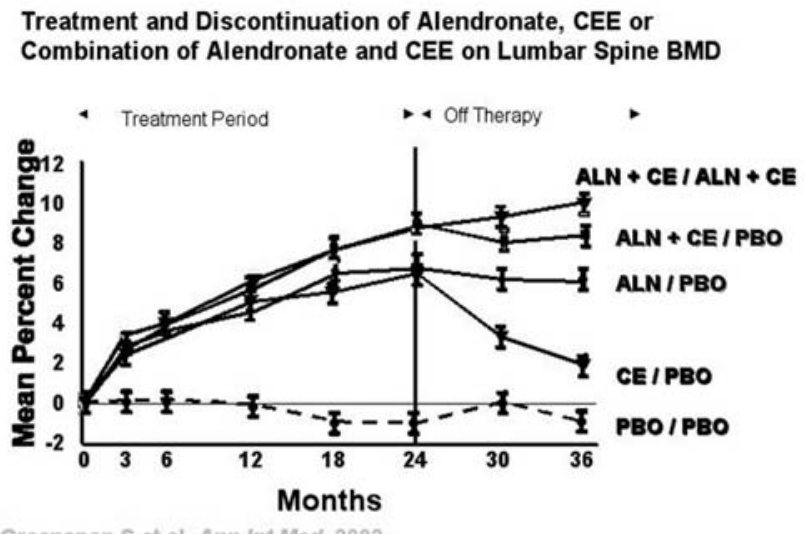

Figure 4. Treatment and discontinuation of alendronate, conjugated equine estrogens, or the combination on lumbar spine bone mineral density.

Hysterectomized women were randomized to alendronate (10 mg/d), CEE (0.625 mg/d), the combination of alendronate and CEE or placebo for 2 years of treatment. At the 24 month time point, subjects were switched to placebo in the alendronate and CEE groups, and the group on both therapies were randomized to either continue on combination therapy or switched to placebo. (Adapted from Greenspan S, et al. Ann Int Med 2002;137(1 1):875-83) 
vertebral sites in women treated with combination therapy than with either CEE or alendronate alone. There was an increase of BMD in the combination therapy group of $5.9 \%$ at the total hip and $10.4 \%$ at the lumbar spine. With alendronate therapy alone, there was a significant increase in total hip BMD compared to CEE with or without MPA ( $4.2 \%$ vs. $3.0 \%$; $<<0.05$, respectively) (47).

Combination therapy of teriparatide (recombinant human parathyroid hormone 1-34), an anabolic agent, and HT has also been studied. Women who had been on HT for at least two years were randomized to either remain on HT and received daily PTH 1-34 (25 $\mathrm{ug} / \mathrm{d}$ ), subcutaneously for three years. The other group remained on HT alone. Subjects in the combination therapy group increased their bone mass by $13.4 \%$ in the lumbar spine, $4.4 \%$ in the total hip and $3.7 \%$ in the total body. Vertebral fractures were reduced in the women on the combination of PTH plus HT therapy compared to women who did not get teriparatide $(\mathrm{p}<0.02)(48)$. In a smaller study, women received estrogens for one year and then were randomized to either hPTH (1-34) plus estrogen or remain on estrogen alone. In the combination group, lumbar spine BMD increased throughout the course of the study. In contrast to the other study, lumbar spine BMD decreased although not significantly (49).

The main concern with combination therapy is the lack of trials with fracture as an endpoint. The relationship between changes in BMD and fracture reduction is not linear, making it difficult to assess the effects of combination therapies on fracture risk reduction. However, Hochberg et al. published an analysis that demonstrated that the greatest improvements in vertebral $\mathrm{BMD}$ were associated with the greatest reductions in vertebral fractures $(50)$.

\section{HORMONE THERAPY: HOW LONG TO TREAT?}

The findings of the WHI lead to the suggestion that women should be treated with estrogen with the lowest dose for the shortest time possible. Recently, a systematic review has been published to provide evidence for these recommendations (5l). Databases were searched for randomized, double-blind trails of hormone therapy, with or without progestogens, compared to placebo. Fifteen trials were included and assessed for quality and risk ratios for dichotomous outcomes and weighted mean differences for continuous outcomes were calculated. Combined continuous HT significantly increase the risk of venous throm- boembolism or coronary event after one year's use, stroke (after 3 years), breast cancer (after 5 years) and gall bladder disease. Long-term estrogen alone therapy was associated with an increase risk of stroke and gall bladder disease. With long-term use, the benefits of HT included a decrease in fracture incidence and colon cancer. With healthy women over the age of 65 , there was a significant increase in the incidence of dementia with continuous combined HT. There were no trials that focused on younger women, but in a subset of women aged 50-59 years, there was an increased risk in venous thromboembolism with continuous combined HT: however, the absolute risk was very low. There was no increased risk in the younger cohort on estrogen alone.

\section{ARE THERE NON-RESPONDERS TO ESTROGEN THERAPY?}

Estimates of the number of responders vs. nonresponders to estrogen therapy have varied widely, ranging from less than $1 \%$ to greater than $30 \%$ across studies. One of the problems in the identification and comparison of a "nonresponder" to therapy as a standard definition and the difficulties associated with longitudinal measurements of bone mineral density. Within-person variations can result in a subject appearing as a "nonresponder" unless careful replicate measurements are made. In the analysis of the postmenopausal estrogen/progestatin interventions (PEPI) trial, 875 healthy postmenopausal women were randomized to one of 5 treatment groups. Replicate BMD measurements were used to calculate the within-person measurement errors. In addition, a standard definition was developed to classify subjects who were actually losing bone. Only subjects who adhered to the prescribed protocol were included in the results analysis. In the first 12 months, $2.3 \%$ of the subjects lost BMD at the total hip. However, this percentage fell to $0.4 \%$ during the following 12-36 months of the study. This well-defined study indicated that bone loss in women taking HT is rare (52).

In a recently published study that utilized low dose HT, the incidence of continued bone loss was defined as a loss of BMD $>2 \%$ from baseline. In the HOPE trial, changes from baseline in lumbar spine and total hip BMD were compared among treatment groups in an intent-to-treat analysis. At 12 months, < $10 \%$ of women on active treatment lost $>2 \%$ of spinal BMD as compared to $41 \%$ of women on placebo. The exception was the group treated with CEE $0.3 \mathrm{mg} / \mathrm{d}$ and MPA $1.5 \mathrm{mg} / \mathrm{d}$ (16\% of subjects lost $>2 \%$ lumbar 
spine BMD). At 24 months, the percentages of women on HT who lost $>2 \%$ of spine BMD ranged from $4.5 \%$ in the CEE $0.45 \mathrm{mg} / \mathrm{d}$ and MPA $1.5 \mathrm{mg} / \mathrm{d}$ group to $16 \%$ in the CEE $0.3 \mathrm{mg} / \mathrm{d}$ MPA $1.5 \mathrm{mg} / \mathrm{d}$ group and compared to $55 \%$ of women on placebo. Women who lost more than $2 \%$ of lumbar spine or hip BMD had a lesser reduction in biochemical markers of bone turnover. Due to the fact that this trial used the LOCF (Last Observation Carried Forward) procedure, these estimates of bone loss while on HT are conservative (4l).

\section{DISCONTINUATION OF ESTROGEN THERAPY}

The beneficial effects of estrogen on bone mineral density have been well appreciated. However, the effects of withdrawal of therapy have also been well documented. Several studies have demonstrated a marked loss of BMD after discontinuation of HT. This was demonstrated early in postmenopausal women (53) and several controlled trials followed women after discontinuation of therapy. The rate of bone loss is usually comparable to the rate of bone loss at the time of menopause. Epidemiologic studies also support these studies in that reductions in fracture risk that are obtained with HT are lost after discontinuation of therapy. In some studies, women who discontinued therapy had rates of fracture and bone loss similar to those who had never taken HT $(54,55)$.

In a cohort study, 26 women who discontinued HT were followed and compared with three groups of women from the same cohort. The first group was matched for age; the second was a group of untreated women who were within 5 years of the menopause, and a group who continued HT. Over a 4-year period, serum osteocalcin, bone alkaline phosphatase and serum C-telopeptide of type I collagen were performed. Bone mineral density was measured annually at the forearm during the same time period (56). In the cohort that discontinued HT, there was a significant loss of BMD at the radius, with an annual rate of loss that ranged from - 0.7 to $-1.6 \%$ (dependent on the site). There was a marked increase of bone markers after 6 months. Osteocalcin increased $36 \%$, bone alkaline phosphatase increased $23 \%$ and serum CTX increased $120 \%$. In the group that continued $\mathrm{HT}$, there was no substantial change in BMD or bone turnover markers over the 4-year period. The interesting comparison in this cohort included the fact that the rate of bone loss after discontinuation of HT was significantly higher as compared to the accelerated bone loss in age-matched postmenopausal women who never received HT and not different from the rate of loss in women who had been untreated and were within 5 years of menopause. Although this is an observational study with comparisons of BMD at a peripheral site, the women who discontinued HT had a loss of BMD greater than an age-matched population and similar to women who had were untreated throughout the menopausal period.

In one study, comparison of withdrawal of $\mathrm{HT}$ or alendronate was compared. The Early Postmenopausal Intervention Cohort (EPIC) study is a trial in 1,609 postmenopausal women aged $45-59$ years of age. There were 2 strata in the study: the US strata was provided 2.5 $\mathrm{mg} / \mathrm{d}$ of alendronate, $5.0 \mathrm{mg} / \mathrm{d}$ of alendronate, placebo or CEE $0.625 \mathrm{mg} / \mathrm{d}$ plus MPA $5.0 \mathrm{mg} / \mathrm{d}$ and the EU strata received micronized $17 \beta$-estradiol $2.0 \mathrm{mg} / \mathrm{d}$ for 22 days plus norethisterone acetate $1.0 \mathrm{mg}$ daily on days $13-22$ and estradiol $1.0 \mathrm{mg} / \mathrm{d}$ on days $23-28$ of each month. The second strata contained women who had a hysterectomy or a contraindication to HT. The subjects in this stratum were randomized to placebo, $2.5 \mathrm{mg} / \mathrm{d}$ or $5.0 \mathrm{mg} / \mathrm{d}$ of alendronate. BMD was reduced in the placebo groups at all skeletal sites during the first 4 years of treatment and the declines persisted throughout years 5 and 6 . Daily treatment with alendronate $(5 \mathrm{mg} / \mathrm{d})$ increased BMD of the lumbar spine and total hip compared with baseline, and similar findings were noted with $2.5 \mathrm{mg} / \mathrm{d}$ of alendronate. BMD decreased in all women who switched from alendronate to placebo, which occurred at 2 years for some subjects and at 4 years for other subjects. Compared to the $5.0 \mathrm{mg} / \mathrm{d}$ alendronatetreated group, the HT treated women had a slightly greater BMD increase at the spine and similar increases at the hip in stratum 1. However, when HT was discontinued during years 5 and 6 , there were large losses in $\mathrm{BMD}$. The mean changes in BMD in the group that discontinued HT were $-7.7 \%$ at the spine and $-5.2 \%$ at the hip. The mean BMD at the end of 6 years was similar to baseline at the end of 6 years in the HT-treated group that discontinued medication (57).

Other studies have also carefully measured changes in BMD after discontinuation of HT. In a 5year, prospective trial, the treatment and withdrawal effects of HT, calcitriol, HT plus calcitriol or placebo were measured (figure 5) (58). Women aged 65-77 years were randomized to $0.625 \mathrm{mg} / \mathrm{d}$ CEE plus 2.5 $\mathrm{mg} / \mathrm{d}$ MPA (in patients with an intact uterus), calcitriol 0.25 ug twice daily, a combination of both, or placebo. After 3 years of treatment, therapy was discontinued. In this older group, there were no differ- 


\section{Treatment and Discontinuation of Hormone Therapy on Lumbar Spine and Femoral Neck BMD}

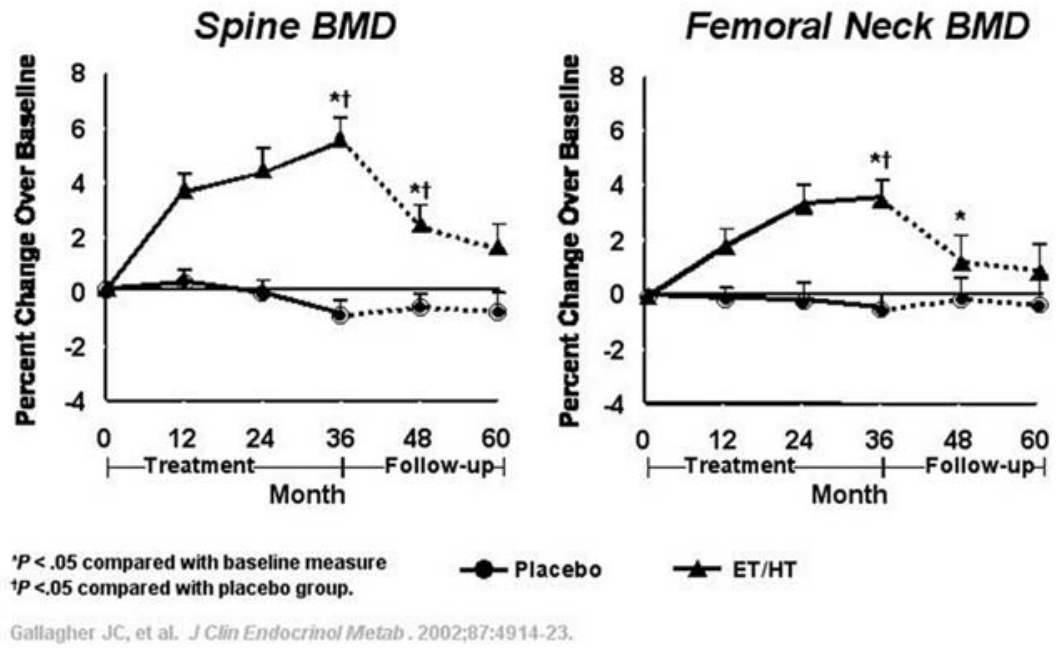

Figure 5. Treatment and discontinuation of hormone therapy on lumbar spine and femoral neck BMD. (Adapted from Gallagher JC, et al. J Clin Endocrinol Metab 2002;87:4912-23)

Elderly women aged 65 to 77 years were randomized to received ET/HT, calcitriol, ET/HT plus calcitriol or placebo and treated for 3 years. Only the treatment arms on ET/HT are represented. After 3 years, treatment was discontinued. ${ }^{*} p<0.05$ compared to baseline measure; $+p<0.05$ compared to placebo.

ences in mean spine BMD compared with baseline during treatment and withdrawal phases. With HT, lumbar spine BMD increased $5.5 \%$ at 3 years, and decreased $3.2 \%$ during year 4 and $0.7 \%$ in year 5 . At year 5 , the mean lumber spine BMD was higher than placebo. At the total hip, there was a significant decrease in BMD with placebo during the first 3 years with continued decreases in years 4 and 5 . In the HT group, total hip BMD increased significantly by $3.6 \%$ at year $3(p<0.0001)$. After discontinuation of HT, there was a fall in total hip BMD of $3.3 \%$ in year 4 and $0.7 \%$ in year 5 . The overall mean change in BMD was not significantly different from that with placebo or at baseline. It is notable that most of the bone loss that occurred with discontinuation of HT was in the first year in this older population.

In the PEPI study, different findings regarding discontinuation of HT were found (59). The initial purpose of this trial was to determine the effects of estrogen, alone or in combination with 1 of 3 different progestogen combinations on hear disease risk factors. Women were between 45 and 64 years of age at recruitment. In a follow-up observational extension study, women were not assigned to randomized treatments and if they continued HT, the treatment was provided by their personal physician. BMD at the hip and spine was measured 3 and 5 years after completion of PEPI. In this final analysis, 97\% (of the original 875 women) participated in the observational study. In the initial study, there were no differences in the lumbar spine or hip BMD outcomes by treatment group, so for the follow-up, all active treatment groups were combined. A total of 495 women were analyzed which represented $57 \%$ of the original cohort. Women who discontinued HT after 1 year of the initial trial had annual rates of BMD change of $-0.54 \%$ at the hip and $-0.81 \%$ at the lumbar spine during the following 2 years. Those women who continued HT during the 3-year randomized clinical trial and then discontinued HT had annual changes of $-1.01 \%$ at the hip and $-1.04 \%$ at the limner spine. The rates of BMD loss among women who stopped HT during or after the randomized clinical trial did not differ significantly from those of women who did not take HT, who lost bone at the rate of around $1 \%$ annually during the first year of the randomized trial and about half that rate afterwards. From these data, the investigators determined that bone is lost at a higher rate after discontinuation of HT. There were several limitations to the study that the authors corrected for, such as the fact that it was a younger group that continued their HT when compared to the overall group. Women with a uterus who were randomized to unopposed CEE were more likely to discontinue treatment due to side effects or adverse events. 
In a trial that determined the rate of bone loss in subjects that were treated with alendronate, estrogen or both agents, an interesting comparison was presented (60). In this RCT, hysterectomized women were treated for 2 years with alendronate, $10 \mathrm{mg} / \mathrm{d}$, $0.625 \mathrm{mg} / \mathrm{d}$ or $\mathrm{CEE}$, both or placebo. At year 3 , women were allocated into five groups in which the women taking placebo, CEE of alendronate were all placed on placebo. The group taking combination therapy were either continued on combination therapy or switched to placebo. Both BMD and bone turnover markers were measured. Women who were taking alendronate or combination therapy and switched to placebo maintained BMD. In contrast, women who were previously taking estrogen and who were switched to placebo experienced a $4.5 \%$ decrease at the spine $(95 \% \mathrm{CI},-5.0 \%$ to $-4.0 \%)$ and $-2.4 \%$ at the trochanter $(95 \% \mathrm{CI},-2.7 \%$ to $-2.1 \%$; $<<0.001$ for both). Changes in biochemical markers did not differ among the groups that discontinued active treatment. These authors concluded that accelerated bone loss is present after withdrawal of estrogen but not seen after alendronate alone or combination of estrogen and alendronate.

It is clear from multiple studies that discontinuation or withdrawal from estrogen results in a decrease in BMD at multiple skeletal sites. However, it is not certain if discontinuation results in a greater fracture risk, and epidemiologic studies provide conflicting results. It has been proposed that the length of treatment might be an important factor in maintaining benefit from fracture risk.

\section{CONCLUSIONS}

Estrogen therapy has proven to increase bone mineral density at all skeletal sites tested. Protection against osteoporotic fractures by estrogen is supported by a wealth of data that includes a meta-analysis of 22 estrogen trials, cohort studies, results from the WHI and Million Women Study, and trials with bone mineral density outcomes (61). However, use of estrogen has its attendant risks, and the risk-to-benefit ratio should be carefully weighed for each individual women.

\section{REFERENCES}

1. Mattson-Jack EpiSource. Available at <http://www. epidb.com/app/fmeLayout.asp>.

2. Johnell O, Kanis JA. An estimate of the worldwide preva- lence, mortality and disability associated with hip fracture. Osteoporos Int 2004; 15:897-902.

3. Ohsfeldt RL, Borisov NN, Sheer RL. Fragility fracture-related direct medical costs in the first year following a nonvertebral fracture in a managed care setting. Osteoporos Int 2006; 17:252-8.

4. US Surgeon General's Report. Available at <http://www. surgeongeneral.gov>.

5. Cummings SR. Melton LJ. Epidemiology and outcomes of osteoporotic fractures. Lancet 2002;359(9319):1761-7.

6. Ettinger B. Vasomotor symptom relief versus unwanted effects: role of estrogen dosage. Am J Med 2005; $118(12 \mathrm{~B}): 74 \mathrm{~S}-8$.

7. Lee $K$, Jessop $H$, Suswillo $R$, Zaman $G$, Lanyon $L$. Endocrinology: bone adaptation requires oestrogen receptor-alpha. Nature 2003:424:389.

8. Bonnelye E, Aubin JE. Review: Estrogen receptor-related receptor $\alpha$ : a mediator of estrogen response in bone. $\mathbf{J}$ Clin Endocrinol Metab 2005;90(5):3115-21.

9. Suda T, Takahashi N, Udagawa N, Jimi E, Gillespie MT, Martin TJ. Modulation of osteoclast differentiation and function by the new members of the tumor necrosis factor receptor and ligand families. Endocr Rev 1999;20:345-57.

10. Raisz Lawrence $G$. Pathogenesis of osteoporosis: concepts, conflicts, and prospects. J Clin Invest 2005; $115(12): 3318-25$.

11. Bucay N, Sarosi I, Dunstan CR, Morony S, Tarpley J, Capparelli $C$, et al. Osteoprotegerin-deficient mice develop early onset osteoporosis and arterial calcification. Genes Dev 1998; 12:1260-8.

12. Eghbali-Fatourechi $G$, Khosla S, Sanyal A, Boyle WJ, Lacey DL, Riggs BL. Role of RANK ligand in mediating increased bone resorption in early postmenopausal women. J Clin Invest 2003;1 11 (8):1221-30.

13. Smith EP, Boyd J, Frank GR, Takahashi H, Cohen RM, Specker B, et al. Estrogen resistance caused by a mutation in the estrogen-receptor gene in a man. $\mathbf{N}$ Engl $\mathbf{J}$ Med 1994:331:1056-61. (Erratum: N Engl J Med 1995; $332: 131$.)

14. Morishima A, Grumbach MM, Simpson ER, Fisher C, Qin $\mathrm{K}$. Aromatase deficiency in male and female siblings caused by a novel mutation and the physiological role of estrogens. J Clin Endocrinol Metab 1995;80: 3689-98.

15. Carani C, Qin K, Simoni M, Faustini-Fustini M, Serpente S, Boyd J, et al. Effect of testosterone and estradiol in a man with aromatase deficiency. N Engl J Med 1997:337:91-5.

16. loannidis JPA, Ralston SH, Bennett ST, Brandi ML, Grinberg D, Karassa FB, et al. Differential genetic effects of ESR1 gene polymorphisms on osteoporosis outcomes. JAMA 2004;292(17):2105-14.

17. Falahati-Nini A, Riggs BL, Atkinson EJ, O'Fallon WM, Eastell R, Khosla S. Relative contributions of testosterone and estrogen in regulating bone resorption and formation in normal elderly men. J Clin Invest 2000; 106(12):1553-60.

18. Richelson LS, Wahner HW, Melton LJ, III, Riggs BL. Relative contributions of aging and estrogen deficiency to post- 
menopausal bone loss. N Engl J Med 1984;31 1:1273-5.

19. Gallagher JC. Role of estrogens in the management of postmenopausal bone loss. Rheum Dis Clin North Am 2001;27:143-62.

20. Ettinger B, Pressman A, Sklarin P, Bauer DC, Cauley JA, Cummings SR. Associations between low levels of serum estradiol, bone density, and fractures among elderly women: The study of osteoporotic fractures. J Clin Endocrinol Metab 1998;83:2239-43.

21. Rapuri JPB, Gallagher C, Haynatzki G. Endogenous levels of serum estradiol and sex hormone binding globulin determine bone mineral density, bone remodeling, the rate of bone loss, and response to treatment with estrogen in elderly women. J Clin Endocrinol Metab 2004;89(10):4954-62.

22. Cauley JA, Seeley DG, Ensrud K, Ettinger B, Black D, Cummings SR. Estrogen replacement therapy and fractures in older women: Study of Osteoporotic Fracture Research Group. Ann Intern Med 1995;122(1):9-16.

23. Anonymous. Effects of hormone therapy on bone mineral density: results from the postmenopausal estrogen/progestin interventions (PEPI) trial. The writing group for the PEPI. JAMA 1996:276:1389-96.

24. The Women's Health Initiative Steering Committee. Risks and benefits of estrogen plus progestin in healthy postmenopausal women: Principal results from the women's health initiative randomized controlled trial. JAMA 2002;288(3):321-33.

25. Cauley JA, Robbins J, Chen Z, Cummings SR, Jackson $R D$, LaCroix $A Z$, et al. Effects of estrogen plus progestin on risk of fracture and bone mineral density: the women's health initiative randomized trial. JAMA 2003;290(13): 1729-38

26. The Women's Health Initiative Steering Committee. Effects of conjugated equine estrogen in postmenopausal women with hysterectomy. JAMA 2004;291(14): 1701-12.

27. Black DM, Cummings SR, Karpf DB, Cauley JA, Thompson DE, Nevitt MC, et al. Randomized trial of effect of alendronate on risk of fracture in women with existing vertebral fractures. Lancet 1996:348:1535-41.

28. Harris ST, Watts NB, Genant HK, McKeever CD, Hangartner T, Keller $\mathrm{M}$, et al. Effects of risedronate treatment on vertebral and nonvertebral fractures in women with postmenopausal osteoporosis: a randomized controlled trial. JAMA 1999;282:1344-52.

29. McClung MR, Geusens P, Miller PD, Zippel H, Bensen WG, Roux C, et al. Effect of risedronate on the risk of hip fracture in elderly women. N Engl J Med 2001;344:333-40.

30. Cummings SR, Black DM, Thompson DE, Applegate WB, Barrett-Connor $E$, Musliner TA, et al. Effect of alendronate on risk of fracture in women with low bone density but without vertebral fractures: results from the fracture intervention trial. JAMA 1998;280:2077-82.

31. Shapiro S. Risks of estrogen plus progestin therapy: a sensitivity analysis of findings in the Women's Health Initiative randomized controlled trial. Climacteric 2003; 6:302-10.

32. Ettinger B, Grady D, Tosteson AN, Pressman A, Macer JL. Effect of the Women's Health Initiative on Women's Decisions to Discontinue Postmenopausal Hormone Therapy. Obstet Gynecol 2003; 102(6): 1225-32.
33. Banks E, Beral V, Reeves G, Balkwill A, Barnes I; Million Women Study Collaborators. Fracture incidence in relation to the pattern of use of hormone therapy in postmenopausal women. JAMA 2004:291(18):2212-20.

34. Wells $G$, Tugwell P, Shea B, Guyatt G, Peterson J, Zytaruk $\mathrm{N}$, et al; Osteoporosis Methodology Group and The Osteoporosis Research Advisory Group. Meta-analysis of the efficacy of hormone replacement therapy in treating and preventing osteoporosis in postmenopausal women. Endocr Rev 2002:23(4):529-39.

35. NIH Consensus Development Conference on Osteoporosis. Available at <http://www.consensus.nih.gov>.

36. Ahlborg $\mathrm{HG}$, Johnell $\mathrm{O}$, Turner $\mathrm{CH}$, Rannevik $\mathrm{G}$, Karlsson MK. Bone loss and bone size after menopause. N Engl J Med 2003;349(4):327-34

37. Greenspan SL, Beck TJ, Resnick NM, Bhattacharya R, Parker RA. Effect of hormone replacement, alendronate, or combination therapy on hip structural geometry: A 3year, double-blind, placebo-controlled clinical trial. J Bone Miner Res 2005;20(9): 1525-32.

38. Prestwood KM, Kenny AM, Kleppinger A, Kulldorff M. Ultralow-dose micronized 17-beta estradiol and bone density and bone metabolism in older women: a randomized controlled trial. JAMA 2003:290:1042-8.

39. Ettinger B, Genant HK, Cann CE. Postmenopausal bone loss is prevented by treatment with low-dosage estrogen with calcium. Ann Intern Med 1987;106(1):40-5

40. Lindsay R, Gallagher JC, Kleerekoper M, Pickar JH. Bone response to treatment with lower doses of conjugated estrogens with and without medroxyprogesterone acetate in early postmenopausal women. Osteoporos Int 2005; 16:372-9.

41. Recker RR, Davies KM, Dowd RM, Heaney RP. The effect of low-dose continuous estrogen and progesterone therapy with calcium and vitamin D on bone in elderly women. A randomized, controlled trial. Ann Intern Med 1999; 130:897-904.

42. Warming $L$, Ravn $P$, Christiansen $C$. Levonorgestrel and $17 \mathrm{~b}$-estradiol given transdermally for the prevention of postmenopausal osteoporosis. Maturitas 2005;50:78-85.

43. Weiss SR, Ellman H, Dolker M. A randomized controlled trial of four doses of transdermal estradiol for preventing postmenopausal bone loss. Obstet Gynecol 1999:94(3):330-6.

44. Genant HK, Lucas J, Weiss S, Akin M, Emkey R, McNaneyFlint $H$, et al. Low-dose esterified estrogen therapy: effects on bone, plasma estradiol concentrations, endometrium, and lipid levels. Estratab/Osteoporosis Study Group. Arch Intern Med 1997;157:2609-15.

45. Ettinger B, Pressman A, Van Gessel A. Low-dosage esterified estrogens opposed by progestin at 6-month intervals. Obstet Gynecol 2001;98(2):205-11.

46. Bone HG, Greenspan SL, McKeever C, Bell N, Davidson $M$, Downs RW, et al. Alendronate and estrogen effects in postmenopausal women with low bone mineral density. J Clin Endocrinol Metab 2000;85:720-6.

47. Greenspan SL, Resnick NM, Parker RA. Combination therapy with hormone replacement and alendronate for prevention of bone loss in elderly women: A randomized controlled trial. JAMA 2003;289(19):2525-33. 
48. Cosman F, Nieves J, Woelfert L, Formica C, Gordon S, Shen $V$, et al. Parathyroid hormone added to established hormone therapy: Effects on vertebral fracture and maintenance of bone mass after parathyroid hormone withdrawal. J Bone Miner Res 2001;16(5):925-32.

49. Lindsay R, Nieves J, Formica C, Henneman E, Woelfert L, Shen $V$, et al. Randomised controlled study of effect of parathyroid hormone on vertebral-bone mass and fracture incidence among postmenopausal women on oestrogen with osteoporosis. Lancet 1997;350:550-5.

50. Hochberg MC, Greenspan S, Wasnich RD, Miller P, Thompson DE, Ross PD. Changes in bone density and turnover explain the reductions in incidence of non-vertebral fractures that occur during treatment with antiresorptive agents. J Clin Endocrinol Metab 2002;87:1586-92.

51. Farquhar CM, Marjoribanks J, Lethaby A, Lamberts $Q$, Suckling JA; Cochrane HT Study Group. The Cochrane Database of Systematic Reviews: Long term hormone therapy for perimenopausal and postmenopausal women. Cochrane Database Syst Rev 2005:(3): CD004143.

52. Greendale GA, Wells B, Marcus R, Barrett-Connor E. How many women lose bone mineral density while taking hormone replacement therapy? Results from the postmenopausal estrogen/progestin interventions trial. Arch Intern Med 2000; 160:3065-71.

53. Lindsay R, Hart DM, MacLean A, Clark AC, Kraszewski A, Garwood J. Bone response to termination of estrogen treatment. Lancet 1978; 1:1325-7.

54. Michaelsson K, Baron JA, Johnell O, Persson I, Ljunghall S. Variation in the efficacy of hormone replacement therapy in the prevention of hip fracture. Swedish Hip Fracture Study Group. Osteoporos Int 1998:8:540-6.

55. Cauley JA, Zmuda JM, Ensrud KE, Bauer DC, Ettinger B Study of Osteoporotic Fractures Research Group. Timing of estrogen replacement therapy for optimal osteoporosis prevention. J Clin Endocrinol Metab 2001;86:5700-5.
56. Sornay-Rendu E, Garnero P, Munoz F, Duboeuf F, Delmas PD. Effect of withdrawal of hormone replacement therapy on bone mass and bone turnover: the OFELY study. Bone 2003;33:159-66.

57. Wasnich RD, Bagger YZ, Hosking DJ, McClung MR, Wu M, Mantz AM, et al. Changes in bone density and turnover after alendronate or estrogen withdrawal. Menopause 2004; 11 (6):622-30.

58. Gallagher JC, Rapuri PB, Haynatzki G, Detter JR. Effect of discontinuation of estrogen, calcitriol, and the combination of both on bone density and bone markers. J Clin Endocrinol Metab 2002;87(1 1):4914-23.

59. Greendale GA, Espeland M, Slone S, Marcus R, BarrettConnor E; PEPI Safety Follow-Up Study (PSFS) Investigators. Bone mass response to discontinuation of long-term hormone replacement therapy: Results from the postmenopausal estrogen/progestin interventions (PEPI) safety follow-up study. Arch Intern Med 2002; 162:665-72.

60. Greenspan SL, Emkey RD, Bone HG, Weiss SR, Bell NH, Downs RW, et al. Significant differential effects of alendronate, estrogen, or combination therapy on the rate of bone loss after discontinuation of treatment of postmenopausal osteoporosis: A randomized, double-blind, placebo-controlled trial. Ann Intern Med 2002;137(11): 875-83.

61. Nelson HD, Humphrey LL, Nygren P, Teutsch SM, Allan JD. Postmenopausal hormone replacement therapy: Scientific review. JAMA 2002;288(7):872-81.

\section{Address for correspondence:}

Lorraine A. Fitzpatrick

Amgen, Inc.

One Amgen Center Drive

Thousand Oaks, CA 91361

E-mail: Ifitzpat@amgen.com 